\title{
Aqueous Bilayers of Glutamate-Based Double-Chain Ammonium Amphiphiles II. Improvement of Polymerization and Membrane Characteristics by Ether-Linked Alkyl Tails ${ }^{1,2}$
}

\author{
Shinji Kato and Toyoki KunITAKE* \\ Department of Organic Synthesis, Faculty of Engineering, \\ Kyushu University, Fukuoka 812, Japan
}

(Received June 21, 1990)

\begin{abstract}
Photopolymerization was conducted for aqueous bilayer membranes of glutamate-based double-chain ammonium amphiphiles which have the ether linkage in the alkyl tail portion and the acrylate moiety attached to the ammonium head. The polymerization readily proceeded to completion $\left(\bar{M}_{w} \sim 10^{7}\right)$ in contrast to that of related bilayers which lack the ether linkage. The reactivity difference was particularly large in the polymerization in the crystalline state. According to DSC measurement, circular dichroism, and fluorescence spectroscopy, the bilayer polymerized in the liquid crystalline state showed lessened side chain alignment, whereas regular side-chain packing was maintained in the polymerization in the crystalline state. Re-dispersion in water was not possible for the former polymer, though possible for the latter. These different properties may be attributed to the steric difference in the main chain portion which, however, could not be detected by $400 \mathrm{MHz}{ }^{1} \mathrm{H}-\mathrm{NMR}$ spectroscopy.

KEY WORDS Bilayer Membrane/Polymerized Bilayer/Amphiphile / Phase Transition / Electron Microscopy / Molecular Organization /
\end{abstract}

It has been expected that covalent linking of component molecules by polymerization would stabilize aqueous bilayer vesicles and facilitate their uses in practical applications such as controlled drug delivery. ${ }^{3,4}$ Many of the past examples of polymerized vesicles faced a dilemma of efficient polymerization at the expense of lost bilayer characteristics. In our previous investigation on this topic, ${ }^{2}$ we introduced the acrylate unit at the hydrophilic head of glutamate-based double-chain ammonium amphiphiles and scrutinized the molecular organization of the polymerized bilayers by a combination of thermal and spectral measurements. The polymerization was suppressed in crystalline bilayer states. The polymerized bilayers in water showed large hystereses. These results suggested that the polymer chain in the hydrophilic region

\footnotetext{
* To whom all correspondence should be addressed.
}

interferred with facile organization of the side chain alkyl groups.

This disadvantage is partially remedied by introduction of hydrophilic spacer units in between these two portions. We showed that this approach is effective for bilayer formation from prepolymerized amphiphiles. ${ }^{5}$ Elbert, Laschewsky and Ringsdorf similarly succeeded in decoupling of the motion of these two portions in single-component bilayer membranes. $^{6}$

We found recently that the presence of ether oxygen in the alkyl tail e.g., 1 and 2, imparted the aggregation morphology with surprising flexibility without losing the regular side-chain alignment. $^{7}$ It was perceived that the ether oxygen in the alkyl tail is efficient for decoupling of the motion of the polymeric chain and the alkyl tail more than the 

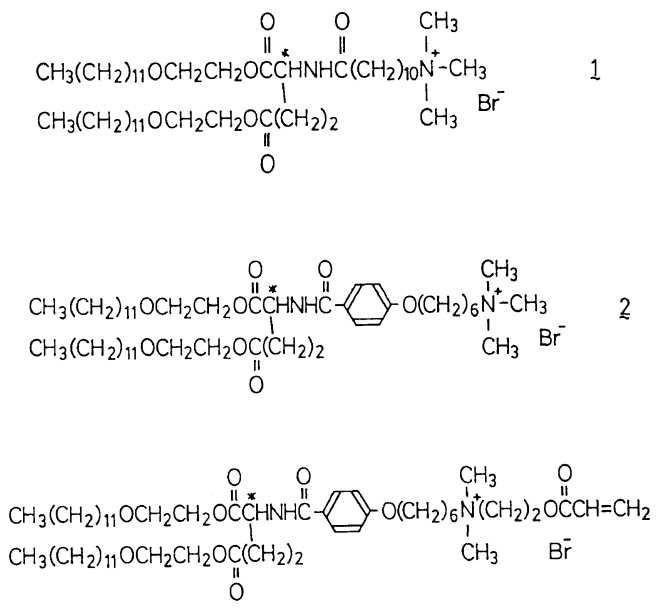

$32\left(\mathrm{C}_{12} \mathrm{OC}_{2}\right)-\mathrm{L}-\mathrm{GluPhC} \mathrm{N}_{6} \mathrm{NAC}^{+}$
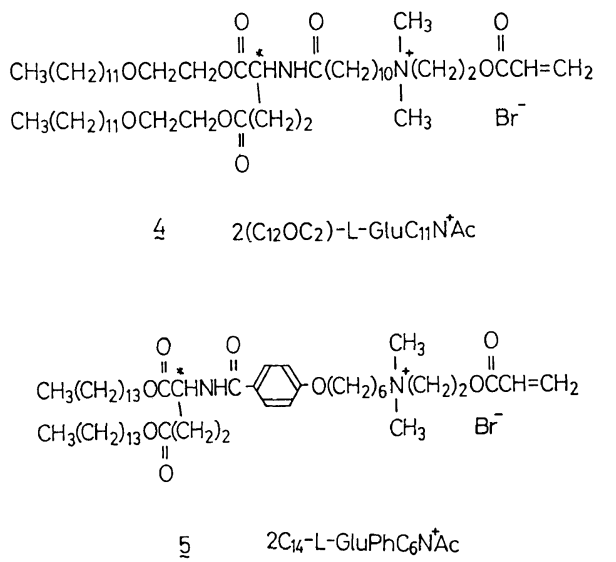

hydrophilic oxyethylene chain in the spacer portion as in ref 6 . We therefore prepared polymerizable double-chain amphiphiles $\mathbf{3}$ and 4 and compared their aggregation and polymerization characteristics with those of a related amphiphile $\mathbf{5}$.

\section{EXPERIMENTAL}

Preparation of $O, O^{\prime}-B i s(2-$ dodecyloxyethyl $)-N$ [ $p$ - $\left\{N^{\prime}\right.$-2-acrylyloxyethyl $)-N^{\prime}, N^{\prime}$-dimethylammoniohexyloxy\}benzoyl]-L-glutamate Bromide (3, 2( $\left.\mathrm{C}_{12} \mathrm{OC}_{2}\right)$-L-GluPhC $\left.\mathrm{C}_{6} \mathrm{~N}^{+} \mathrm{Ac}\right)$ L-Glutamic acid $(2.9 \mathrm{~g}, 0.02 \mathrm{~mol})$, ethylene glycol mono $n$-dodecyl ether (Nikko Chemicals Co.) $(10.0 \mathrm{~g}, 0.043 \mathrm{~mol})$, and $p$-toluenesulfonic acid $(7.5 \mathrm{~g}, 0.039 \mathrm{~mol})$ were dissolved in toluene, and the mixture was heated under stirring. Heating was continued until the theoretical amount of water was collected in a Dean-Stark trap. Then, toluene was removed in vacuo, and the residue was dissolved in chloroform. This solution was washed with an aqueous solution of the theoretical amount of sodium carbonate for neutralization and with water. After drying over sodium sulfate, chloroform was removed in vacuo, and the residue was dissolved in acetone. The theoretical amount of conc. hydrochloric acid was added, and the precipitated hydrochloride was recrystallized from acetone to give colorless crystals of the ester product in a yield of $5.83 \mathrm{~g}(47.6 \%)$ : $\mathrm{mp} 96.0 \sim 97.0^{\circ} \mathrm{C} ;{ }^{1} \mathrm{H} \mathrm{NMR}$ $\left(\mathrm{CDCl}_{3}, \quad \mathrm{TMS}\right), \quad 0.8-1.8 \mathrm{ppm} \quad(\mathrm{m}, \quad 48 \mathrm{H})$, $2.0-2.7(\mathrm{~m}, 3 \mathrm{H}), 3.3-3.8(\mathrm{~m}, 8 \mathrm{H}), 4.0-4.4$ (m, O- $\left.\mathrm{CH}_{2}, 4 \mathrm{H}\right), 8.7-8.9\left(\mathrm{~S}, \mathrm{~N}^{+}-\mathrm{H} 3 \mathrm{H}\right)$; IR $\left(\mathrm{KBr}, \mathrm{cm}^{-1}\right) 1740\left(v_{\mathrm{C}=\mathrm{O}}\right.$, ester $), 1130\left(v_{\mathrm{C}-\mathrm{O}}\right.$, ether).

Bis(2-dodecyloxyethyl)-L-glutamate hydrochloride $(1.0 \mathrm{~g}, 0.0016 \mathrm{~mol})$ and triethylamine $(0.65 \mathrm{~g}, 0.0065 \mathrm{~mol})$ were dissolved in dry tetrahydrofuran (THF), and the mixture was stirred at room temperature. After removing precipitated triethylamine hydrochloride, the solution was added dropwise to a dry THF solution of $p$-(6-bromohexyloxy)benzoic acid $(0.60 \mathrm{~g}, 0.002 \mathrm{~mol})\left(\mathrm{mp} 135.0 \rightarrow 151.0^{\circ} \mathrm{C}\right.$, the arrow indicating the presence of liquidcrystalline region) and diethylcyanophosphonate (DEPC, Aldrich Co.) $(0.49 \mathrm{~g}, 0.003 \mathrm{~mol})$ over $15 \mathrm{~min}$ under stirring on an ice bath. The mixture was further stirred at room temperature for $20 \mathrm{~h}$. THF was removed in vacuo, and the residue was recrystallized from methanol to give colorless powder of the amide product in a yield of $1.14 \mathrm{~g}(81.0 \%)$ : $\mathrm{mp}$ $49.0 \sim 49.5^{\circ} \mathrm{C} ; \quad{ }^{1} \mathrm{H} \quad \mathrm{NMR} \quad\left(\mathrm{CDCl}_{3}, \quad \mathrm{TMS}\right)$ $0.8-1.8 \mathrm{ppm}(\mathrm{m}, 56 \mathrm{H}), 1.9-2.6(\mathrm{~m}, 3 \mathrm{H})$, $3.2-3.8(\mathrm{~m}, 10 \mathrm{H}), 3.9-4.3\left(\mathrm{~m}, \mathrm{O}-\mathrm{CH}_{2}, 6 \mathrm{H}\right)$ 6.7-7.9 (phenyl and amide, 5H); IR ( $\mathrm{KBr}$, 
$\left.\mathrm{cm}^{-1}\right), 1740\left(v_{\mathrm{C}=\mathrm{o}}\right.$, ester $), 1640\left(v_{\mathrm{C}=\mathrm{o}}\right.$, amide $)$, $1130\left(v_{\mathrm{C}-\mathrm{o}}\right.$, ether).

$O, O^{\prime}$-Bis(2-dodecyloxyethyl)- $N$ - $\{p$-(6-bromohexyloxy)benzoyl $\}$-L-glutamate $(1.13 \mathrm{~g}$, $0.0013 \mathrm{~mol})$ and 2-(dimethylamino)ethyl acrylate (Wako Pure Chemical Co., bp $79^{\circ} \mathrm{C} / 30$ $\mathrm{mmHg})(3.58 \mathrm{~g}, 0.025 \mathrm{~mol})$ were dissolved in dry acetonitrile and the mixture was stirred at ca. $50^{\circ} \mathrm{C}$ for $162 \mathrm{~h}$ in the dark. A spatulaful of dibutylhydroxytoluene was added as a polymerization inhibitor. Acetonitrile was removed in vacuo, and the residue was recrystallized twice from ethyl acetate to give colorless powder of 3 in a yield of $0.55 \mathrm{~g}$ (42.0\%): $\mathrm{mp} 52.0 \rightarrow 96.0^{\circ} \mathrm{C} ;{ }^{1} \mathrm{H} \mathrm{NMR}\left(\mathrm{CDCl}_{3}\right.$, TMS) $0.8-1.8 \mathrm{ppm}(\mathrm{m}, 56 \mathrm{H}), 1.9-2.6(\mathrm{~m}$, $3 \mathrm{H}), 3.2-3.8(\mathrm{~m}, 18 \mathrm{H}), 3.9-4.3\left(\mathrm{~m}, \mathrm{O}-\mathrm{CH}_{2}\right.$, $8 \mathrm{H}$ ), 5.8-6.4 (vinyl, 3H), 6.7-7.9 (phenyl and amide, $5 \mathrm{H})$; IR $\left(\mathrm{KBr}, \mathrm{cm}^{-1}\right), 1740\left(v_{\mathrm{C}=0}\right.$, ester $)$, $1640\left(v_{\mathrm{C}=0}\right.$, amide), 1120 ( $v_{\mathrm{C}-\mathrm{o}}$, ether). Anal. Calcd for $\mathrm{C}_{53} \mathrm{H}_{93} \mathrm{O}_{10} \mathrm{~N}_{2} \mathrm{Br} \cdot 2 \mathrm{H}_{2} \mathrm{O}$ : C, $61.55 \%$; $\mathrm{H}, 9.45 \%$; N, $2.71 \%$. Found: C, $61.50 \%$; $9.37 \% ; \mathrm{N}, 2.65 \%$.

Preparation of $O, O^{\prime}-B i s(2-$ dodecyloxyethyl $)-N$ $\left[N^{\prime}\right.$-(2-acrylyloxyethyl)- $N^{\prime}, N^{\prime}$-dimethylammonioundecanoyl]-L-glutamate Bromide $\left(4,2\left(C_{12} O C_{2}\right)\right.$-L-GluC $\left.C_{11} N^{+} A c\right)$

Bis(2-dodecyloxyethyl)-L-glutamate hydrochloride $(1.0 \mathrm{~g}, 0.0016 \mathrm{~mol})$ and triethylamine $(0.51 \mathrm{~g}, 0.0051 \mathrm{~mol})$ were dissolved in dry THF, and the mixture was stirred at room temperature. After precipitates of triethylamine hydrochloride were removed, 11-bromoundecanoyl chloride $(0.85 \mathrm{~g}, 0.003 \mathrm{~mol})$ in dry THF was added dropwise over 30 min under stirring in an ice bath. The mixture was further stirred at room temperature for $24 \mathrm{~h}$, the precipitates were removed, and THF was distilled off in vacuo. The residue was recrystallized from methanol to give colorless flakes of the amide product in a yield of $1.16 \mathrm{~g}(87.2 \%)$ : $\mathrm{mp}$ $60.0-60.5^{\circ} \mathrm{C} ;{ }^{1} \mathrm{H} \quad \mathrm{NMR} \quad\left(\mathrm{CDCl}_{3}, \quad \mathrm{TMS}\right)$ $0.8-2.0 \mathrm{ppm}(\mathrm{m}, 64 \mathrm{H}), 2.0-2.7(\mathrm{~m}, 5 \mathrm{H})$, $3.2-3.8(\mathrm{~m}, 10 \mathrm{H}), 3.9-4.4\left(\mathrm{~m}, \mathrm{O}-\mathrm{CH}_{2}, 4 \mathrm{H}\right)$, 6.7-6.9 (d, amide, $1 \mathrm{H})$; IR $\left(\mathrm{KBr}, \mathrm{cm}^{-1}\right), 1740$
$\left(v_{\mathrm{C}=0}\right.$, ester $), 1640\left(v_{\mathrm{C}=0}\right.$, amide $), 1130\left(v_{\mathrm{C}-\mathrm{o}}\right.$, ether).

Subsequent quaternization with 2-dimethylaminoethyl acrylate was conducted as described above. The product was recrystallized from ethyl acetate to give colorless powder of $\mathbf{4}$ in a $50 \%$ yield: $\mathrm{mp} 37.0 \rightarrow 75.0^{\circ} \mathrm{C} ;{ }^{1} \mathrm{H}$ NMR $\left(\mathrm{CDCl}_{3}, \mathrm{TMS}\right) \quad 0.8-2.0 \mathrm{ppm}(\mathrm{m}, 64 \mathrm{H}), 2.0$ $2.7(\mathrm{~m}, 64 \mathrm{H}), 3.2-3.8(\mathrm{~m}, 18 \mathrm{H}), 3.9-4.4(\mathrm{~m}$, $6 \mathrm{H}), 5.7-6.5$ (vinyl, $3 \mathrm{H})$; IR $\left(\mathrm{KBr}, \mathrm{cm}^{-1}\right)$, $1740\left(v_{\mathrm{C}=0}\right.$, ester), $1650\left(v_{\mathrm{C}=0}\right.$, amide), 1130 ( $v_{\mathrm{C}-\mathrm{O}}$, ether). Anal. Calcd for $\mathrm{C}_{51} \mathrm{H}_{97} \mathrm{O}_{9} \mathrm{~N}_{2} \mathrm{Br}$. $1.5 \mathrm{H}_{2} \mathrm{O}: \mathrm{C}, 61.92 \%$; H, $10.19 \% ; \mathrm{N}, 2.83 \%$. Found: C, $61.95 \%$; H, 10.04\%; N, 2.96\%.

Amphiphile $5\left(2 \mathrm{C}_{14}\right.$-L-GluPhC $\left.{ }_{6} \mathrm{~N}^{+} \mathrm{Ac}\right)$ was synthesized by essentially the same manner as that for 3. The preparation procedure of the $\omega$-halo precursor and the final product were essentially the same as given elsewhere ${ }^{2,8}$; colorless powder, yield from the $\omega$-halo precursor: $63.0 \%, \mathrm{mp} 108.5 \rightarrow 145.0^{\circ} \mathrm{C} ;{ }^{1} \mathrm{H}$ NMR $\left(\mathrm{CDCl}_{3}, \mathrm{TMS}\right), 0.7-2.0 \mathrm{ppm}(\mathrm{m}, 64 \mathrm{H})$, $2.1-2.7(\mathrm{~m}, 3 \mathrm{H}), 3.2-3.8(\mathrm{~m}, 10 \mathrm{H}), 3.8-4.4$ (m, $\left.-\mathrm{OCH}_{2}, 8 \mathrm{H}\right), 5.8-6.5$ (vinyl, 3H), 6.7-8.0 (phenyl and amide, 5H); IR ( $\left.\mathrm{KBr}, \mathrm{cm}^{-1}\right), 1740$ ( $v_{\mathrm{c}=\mathrm{O}}$, ester), $1640\left(v_{\mathrm{C}=\mathrm{O}}\right.$, amide). Anal. Calcd for $\mathrm{C}_{53} \mathrm{H}_{93} \mathrm{O}_{8} \mathrm{~N}_{2} \mathrm{Br} \cdot \mathrm{H}_{2} \mathrm{O}: \mathrm{C}, 64.68 \% ; \mathrm{H}$, $9.73 \% ; \mathrm{N}, 2.85 \%$. Found: $\mathrm{C}, 64.61 \% ; \mathrm{H}$, $9.59 \% ; \mathrm{N}, 2.85 \%$.

\section{Polymerization}

A known amounts of the polymerizable amphiphile was added to deionized water, and sonicated for $c a .1 \mathrm{~min}$ by a Branson 185 cell disruptor to obtain $20 \mathrm{mM}$ dispersions. They were aged overnight at room temperature in the dark, purged with Ar gas for 30 min, and irradiated without photosensitizer at given temperatures (a water-jacketed holder was used) for $15 \mathrm{~min}$ from a fixed distance of $40 \mathrm{~cm}$ with a $\mathrm{Hg}$ lamp (Ushio ultrahigh-pressure $\mathrm{Hg}$ lamp UI-501C, $250 \mathrm{~W}$ ). No filters were used.

\section{Measurements}

For the molecular weight determination, water was removed in vacuo from the 
polymerized dispersions, and the residual polymers were dissolved in chloroform. Number-average and weight-average molecular weights $\left(\bar{M}_{n}\right.$ and $\left.\bar{M}_{w}\right)$ and the molecular weight distribution were determined by gel permeation chromatography on a highspeed liquid chromatograph (Shimadzu, LC-6A) equipped with a differential refractometer detector (Shimadzu, RID-6A). Chloroform was used as eluent with a flow rate of $1 \mathrm{ml} \mathrm{min}^{-1}$. The column consisted of four types of styrenedivinylbenzene copolymer gels (Shodex KF802, KF-803, KF-804, and KF-805 with exclusion limits of $5 \times 10^{3}, 7 \times 10^{4}, 4 \times 10^{5}$, and $4 \times 10^{6}$, respectively). A calibration curve for molecular weights was obtained by using standard polystyrene samples (Showa Denko Co. $): \bar{M}_{n}=3.6 \times 10^{6} \quad\left(\bar{M}_{w} / \bar{M}_{n}=1.06\right) ; \quad \bar{M}_{n}=$ $1.85 \times 10^{6} \quad\left(\bar{M}_{w} / \bar{M}_{n}=1.06\right), \quad \bar{M}_{n}=4.5 \times 10^{5}$ $\left(\bar{M}_{w} / \bar{M}_{n}=1.08\right), \quad \bar{M}_{n}=1.85 \times 10^{5} \quad\left(\bar{M}_{w} / \bar{M}_{n}=\right.$ $1.06), \quad \bar{M}_{n}=8.7 \times 10^{4} \quad\left(\bar{M}_{w} / \bar{M}_{n}=1.05\right), \quad \bar{M}_{n}=$ $2.8 \times 10^{4} \quad\left(\bar{M}_{w} / \bar{M}_{n}=1.05\right), \quad \bar{M}_{n}=1.02 \times 10^{4}$ $\left(\bar{M}_{w} / \bar{M}_{n}=1.05\right), \quad \bar{M}_{n}=3.55 \times 10^{3} \quad\left(\bar{M}_{w} / \bar{M}_{n}=\right.$ $1.05)$, and $\bar{M}_{n}=1.35 \times 10^{3}\left(\bar{M}_{w} / \bar{M}_{n}=1.07\right)$.

The phase transition behavior was studied with a differential scanning calorimeter (Seiko Instruments SSC/560). Unpolymerized aqueous dispersions $(20 \mathrm{mM})$ were prepared by sonication, and were used after aging overnight. Polymerized aqueous dispersions (20 $\mathrm{mM}$ ) were prepared by photopolymerization as described above, and were used after aging overnight. The measurement was repeated from 0 to $80^{\circ} \mathrm{C}$ at a heating rate of $1^{\circ} \mathrm{C} \mathrm{min}^{-1}$. The detailed procedure is given elsewhere. ${ }^{9}$

Circular dichroism (CD) spectra were obtained with a JASCO J40AS spectropolarimeter. Both of unpolymerized and polymerized aqueous dispersions $(0.1 \mathrm{mM})$ were aged for several days at room temperature, and spectral changes with elevating temperature were recorded. Fluorescence spectra were obtained from the samples prepared as in the case of CD measurement with a Hitachi fluorescence spectrophotometer, Model 650-10S. The excitation wavelength was set at $260 \mathrm{~nm}$, where the benzene ring absorbs.

Aggregate morphology was examined by transmission electron microscopy (Hitachi $\mathrm{H}-600$ ). In the case of unpolymerized aggregates, powder samples were sonicated in saturated aqueous uranyl acetate to obtain $2 \mathrm{mM}$ dispersions, and drops of the dispersions were applied to carbon-coated copper meshes and air-dried at given temperatures. In the case of polymerized aggregates, $20 \mathrm{mM}$ dispersions were diluted to $2 \mathrm{mM}$ with deionized water, and applied to $\mathrm{Cu}$ meshes. Aqueous uranyl acetate was then placed on $\mathrm{Cu}$ meshes and air-dried. During these operations, temperature was kept constant. Polymerized dispersions were not cosonicated with aqueous uranyl acetate, so that the aggregate structure at the time of polymerization was preserved.

\section{RESULTS AND DISCUSSION}

\section{Polymerization}

Amphiphiles 3, 4, and 5 assume bilayer assembly in aqueous dispersion before polymerization, as shown by the experimental data (see below). Bilayer membranes show a phase transition from a crystalline state to a liquid crystalline state due to melting of alkyl side chains. The polymerization behavior was affected by the physical state of assembly, as already found in our previous investigation. ${ }^{2}$ Since the DSC measurement indicated the phase transition temperatures $T_{\mathrm{c}}$, (peak top) of 3,4 , and 5 are $45.0^{\circ} \mathrm{C}, 31.0^{\circ} \mathrm{C}$, and $49.8^{\circ} \mathrm{C}$, respectively, the polymerizations were carried out at temperatures above and below these temperatures.

The progress of polymerization was determined by gel permeation chromatography, since separation of the polymerized and unpolymerized fractions were not easy. Figure 1 shows examples of the GPC chromatogram after polymerization. The conversion is quantitative for bilayer dispersions of $\mathbf{3}$ and $\mathbf{4}$ upon photoirradiation for $15 \mathrm{~min}$ at temperatures above and below $T_{\mathrm{c}}$. The molecular weights 


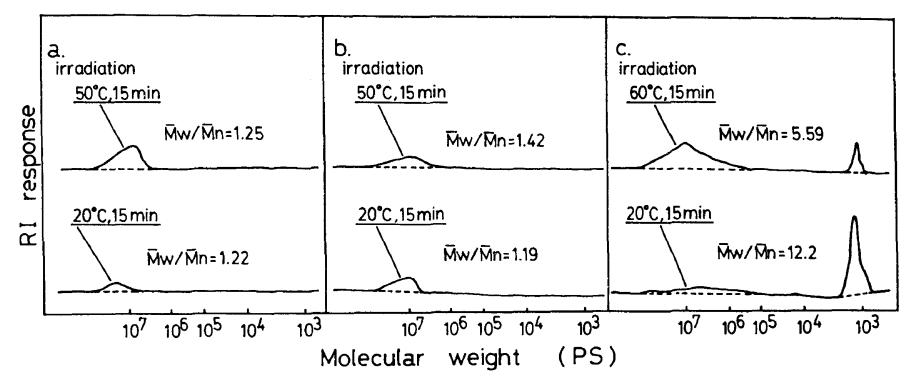

Figure 1. GPC chromatograms of polymerized amphiphiles. (a) $2\left(\mathrm{C}_{12} \mathrm{OC}_{2}\right)$-L-GluPhC $\mathrm{N}^{+} \mathrm{Ac}, 3$; (b) $2\left(\mathrm{C}_{12} \mathrm{OC}_{2}\right)-\mathrm{L}-\mathrm{GluC}_{11} \mathrm{~N}^{+} \mathrm{Ac}, 4$; (c) $2 \mathrm{C}_{14}-\mathrm{L}-\mathrm{GluPhC}_{6} \mathrm{~N}^{+} \mathrm{Ac}$, 5. Eluent, $\mathrm{CHCl}_{3}$; flow rate, $1 \mathrm{ml} \mathrm{min}^{-1}$; Column temperature, $30^{\circ} \mathrm{C}$.

Table I. Polymerization of aqueous bilayers of 3, 4, and 5

\begin{tabular}{|c|c|c|c|c|c|}
\hline \multirow{2}{*}{ Amphiphile } & \multirow{2}{*}{$\begin{array}{l}\text { Polymerization } \\
\text { temperature }\end{array}$} & \multirow{2}{*}{$\frac{\text { Irradiation time }}{\min }$} & \multirow{2}{*}{$\frac{\text { Conversion }}{\%}$} & \multirow{2}{*}{$\bar{M}_{w}$} & \multirow{2}{*}{$\bar{M}_{w} / \bar{M}_{n}$} \\
\hline & & & & & \\
\hline \multirow[t]{6}{*}{3} & $20^{\circ} \mathrm{C}\left(T<T_{\mathrm{c}}\right)$ & 15 & 100 & $1.6 \times 10^{7}$ & 1.22 \\
\hline & & 30 & 100 & $1.5 \times 10^{7}$ & 1.18 \\
\hline & & 60 & 100 & $1.5 \times 10^{7}$ & 1.38 \\
\hline & $50^{\circ} \mathrm{C}\left(T>T_{\mathrm{c}}\right)$ & 15 & 100 & $1.2 \times 10^{7}$ & 1.25 \\
\hline & & 30 & 100 & $1.1 \times 10^{7}$ & 1.52 \\
\hline & & 60 & 100 & $1.2 \times 10^{7}$ & 1.22 \\
\hline \multirow[t]{6}{*}{4} & $20^{\circ} \mathrm{C}\left(T<T_{\mathrm{c}}\right)$ & 15 & 100 & $1.8 \times 10^{7}$ & 1.19 \\
\hline & & 30 & 100 & $1.9 \times 10^{7}$ & 1.27 \\
\hline & & 60 & 100 & $1.8 \times 10^{7}$ & 1.26 \\
\hline & $50^{\circ} \mathrm{C}\left(T>T_{\mathrm{c}}\right)$ & 15 & 100 & $1.7 \times 10^{7}$ & 1.42 \\
\hline & & 30 & 100 & $1.7 \times 10^{7}$ & 1.32 \\
\hline & & 60 & 100 & $1.7 \times 10^{7}$ & 1.28 \\
\hline \multirow[t]{6}{*}{5} & $20^{\circ} \mathrm{C}\left(T<T_{\mathrm{c}}\right)$ & 15 & 27.8 & $7.1 \times 10^{6}$ & 12.2 \\
\hline & & 30 & 29.8 & $3.8 \times 10^{6}$ & 25.0 \\
\hline & & 60 & 48.2 & $3.2 \times 10^{6}$ & 24.0 \\
\hline & $60^{\circ} \mathrm{C}\left(T>T_{\mathrm{c}}\right)$ & 15 & 86.0 & $1.1 \times 10^{7}$ & 5.59 \\
\hline & & 30 & 100 & $1.1 \times 10^{7}$ & 4.38 \\
\hline & & 60 & 100 & $1.2 \times 10^{7}$ & 3.70 \\
\hline
\end{tabular}

[amphiphile $]=20 \mathrm{mM}$.

are extremely high, and their distributions are rather narrow. The results are summarized in Table I.

In contrast, bilayer 5 gave much smaller conversions under similar conditions, and the molecular weight distributions of the polymerized fractions are very large: Figure 1c. The polymerization was complete in $30 \mathrm{~min}$ in the liquid crystalline state $\left(\right.$ at $60^{\circ} \mathrm{C}$ ), whereas it was less than $50 \%$ in the crystalline state even after 60-min irradiation. The molecular weight decreased and the molecular weight distribution increased with the progress of polymerization. It is clear that polymerization proceeded more readily at a temperature above $T_{\mathrm{c}}$.

Apparently, the crystalline packing of alkyl chains interferes with polymerization in the case of bilayer 5. This interference is much relieved in the polymerization in a liquid 
crystalline state. Incorporation of ether oxygen in the tail portion of an alkyl chain as in $\mathbf{3}$ and 4, is surprisingly effective for decoupling of the side-chain packing and the main-chain polymerizability.

\section{Differential Scanning Calorimetry}

The gel-to-liquid crystal phase transition is one of the fundamental properties of the bilayer membrane. We showed previously that the molecular structure and polymerization conditions strongly infiuenced the DSC behavior of the polymerized bilayer. ${ }^{2}$ Therefore, it is interesting to see whether the introduction of ether linkage also affects the DSC behavior of polymerized bilayers.

Figure 2 compares DSC thermograms of aqueous dispersions of $\mathbf{3}$ before and after polymerization. The unpolymerized bilayer gives a sharp endothermic peak at $45^{\circ} \mathrm{C}$ (peak top) reproducibly (Figure 2a). The peak

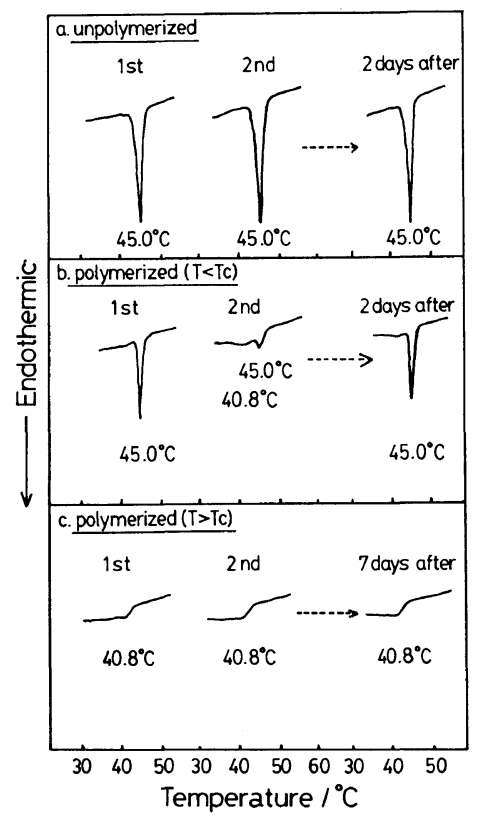

Figure 2. DSC thermograms of aqueous bilayer dispersions of unpolymerized and polymerized $2\left(\mathrm{C}_{12} \mathrm{OC}_{2}\right)-\mathrm{L}-$ $\mathrm{GluPhC}_{6} \mathrm{~N}^{+} \mathrm{Ac}$, 3. $20 \mathrm{mM}$. (a) unpolymerized; (b) polymerized at $20^{\circ} \mathrm{C}$ (below $T_{\mathrm{c}}$ ); (c) polymerized at $50^{\circ} \mathrm{C}$ (above $T_{\mathrm{c}}$ ). sharpness indicates high cooperativity of chain melting. The bilayer polymerized at $T<T_{\mathrm{c}}$ gives similarly a sharp peak at $45^{\circ} \mathrm{C}$ in the first scan, indicating the preservation of the original regular packing of side chains. When this hot sample is immediately cooled to $0^{\circ} \mathrm{C}$ and subjected to a second scan, a very broad peak is found at $45^{\circ} \mathrm{C}$ together with an additional peak at $40.8^{\circ} \mathrm{C}$. The original sharp peak is regenerated upon incubation for two days at room temperature. Realignment of alkyl side chains should occur slowly.

In contrast to the data of Figure $2 b$, the bilayer polymerized at $T>T_{\mathrm{c}}$ gives a very broad peak at $40.8^{\circ} \mathrm{C}$. This DSC behavior does not change in the second scan of the rapidly cooled sample or in the third scan after a prolonged incubation (for 7 days). Thus, the physical state of bilayer during polymerization strongly influences the ease of side-chain packing. It is interesting that the broad peak of Figure $2 \mathrm{c}$ corresponds to the secondary peak observed for the rapidly cooled sample in Figure $2 b$.

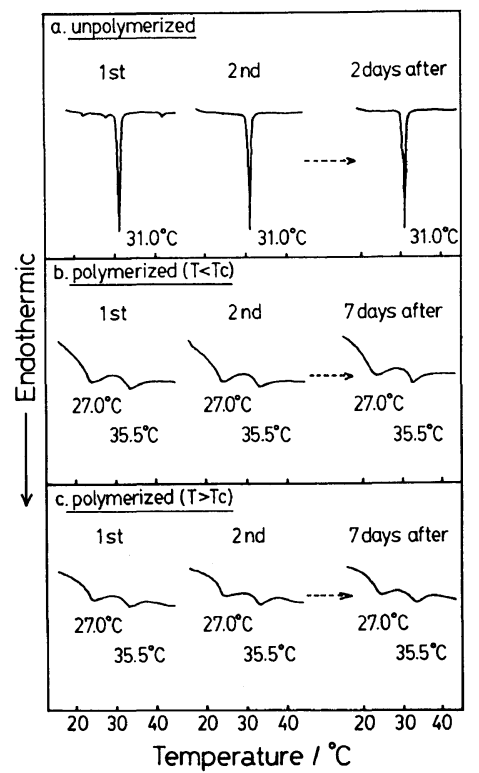

Figure 3. DSC thermograms of aqueous bilayer dispersions of unpolymerized and polymerized $2\left(\mathrm{C}_{12} \mathrm{OC}_{2}\right)-\mathrm{L}-$ $\mathrm{GluC}_{11} \mathrm{~N}^{+} \mathrm{Ac}$, 4. $20 \mathrm{mM}$. (a) unpolymerized; (b) polymerized at $20^{\circ} \mathrm{C}$ (below $T_{\mathrm{c}}$ ); (c) polymerized at $50^{\circ} \mathrm{C}$ (above $T_{\mathrm{c}}$ ). 
Figure 3 gives DSC thermograms of polymerized and unpolymerized bilayers of 4 . The unpolymerized bilayer shows a reproducible sharp peak at $31.0^{\circ} \mathrm{C}$, but the polymerized bilayers invariably give broad peaks at $27.0^{\circ} \mathrm{C}$ and $35.5^{\circ} \mathrm{C}$. Incubation of aqueous dispersions of polymerized bilayers for 7 days did not alter the situation. The physical state of bilayer membrane during polymerization did not influence the DSC behavior in this case.

Bilayer 5 (the reference), when polymerized at $60^{\circ} \mathrm{C}$ for $60 \mathrm{~min}$ ( $c f$. Table I), gave a broad peak at $49-60^{\circ} \mathrm{C}$ and a small peak at $69^{\circ} \mathrm{C}$. The major peak was located at a higher temperature region as compared with the sharp peak (at $50^{\circ} \mathrm{C}$ ) of the unpolymerized bilayer. The second scan gave a very small, broad peak at $50^{\circ} \mathrm{C}$.

The data of Figures 2 and 3 clearly indicate the importance of molecular structure in determining the packing of side chains after polymerization. The presence of benzene ring in the spacer portion is effective for preserving the side-chain alignment, as previously noted

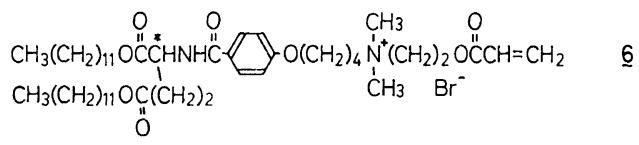

for polymerized bilayers of $6 .{ }^{2}$ In addition, the ether linkage in the alkyl tail enhanced polymerizability (3 vs. 5) and facilitated recovery of the original state of the chain packing. Thus, the presence of both of the benzene ring and the ether linkage as in $\mathbf{3}$ favored the formation of a bilayer which readily polymerizes without losing the regular chain packing.

\section{Circular Dichroism (CD)}

The organization of bilayer assembly is reflected in the spectroscopic property of chromophores in the bilayer component. Bilayer components $\mathbf{3 , 4 , 5}$, are CD active, since they contain the L-glutamic acid residue. The benzene ring attached to this residue enhances $\mathrm{CD}$ intensity, and this information has been used to estimate the long-range interaction of the bilayer component. ${ }^{8}$

Figure 4 summarizes CD spectra of bilayer 3. The unpolymerized bilayer (Figure $4 a$ ) shows evidence of exciton coupling with $[\theta]=-3.8$ $\times 10^{5} \mathrm{deg} \mathrm{cm}^{2} \mathrm{dmol}^{-1}(\lambda=258 \mathrm{~nm})$ in the crystalline state $\left(15^{\circ} \mathrm{C}\right)$. The Cotton effect showed an opposite sign in the case of the trimethylammonium counterpart $2\left([\theta]_{\max }=+1.3 \times\right.$ $10^{5}$ at $\left.263 \mathrm{~nm}\right) .{ }^{10}$ The spatial orientation of the asymmetric carbon and the benzene chro-

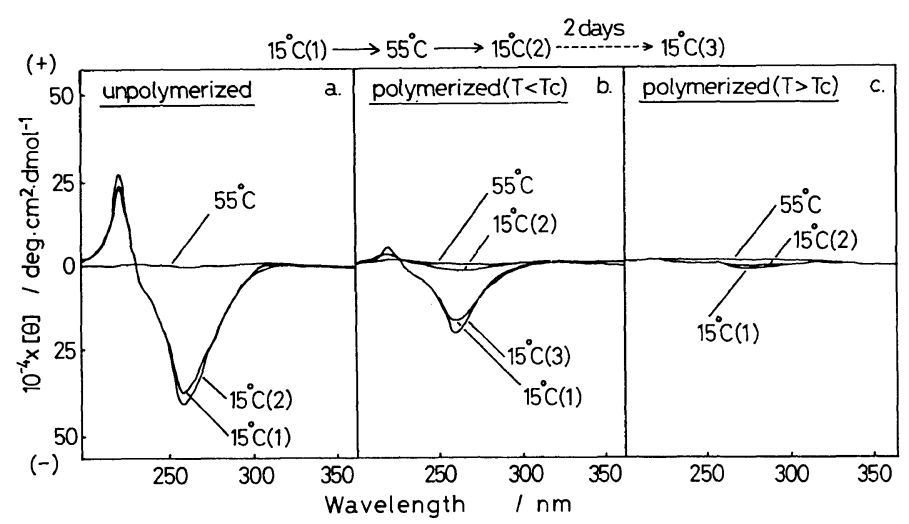

Figure 4. $\mathrm{CD}$ spectra of aqueous bilayer dispersions of unpolymerized and polymerized $2\left(\mathrm{C}_{12} \mathrm{OC}_{2}\right)$-LGluPhC $\mathrm{N}^{+} \mathrm{Ac}$, 3. $0.1 \mathrm{mM}$. (a) unpolymerized; (b) polymerized at $20^{\circ} \mathrm{C}$ (below $T_{\mathrm{c}}$ ); (c) polymerized at $50^{\circ} \mathrm{C}$ (above $T_{\mathrm{c}}$ ). The sequence of measurement: 1 , the original dispersion at $15^{\circ} \mathrm{C} ; 2$, at $55^{\circ} \mathrm{C}$ upon rapid heating from $15^{\circ} \mathrm{C} ; 3$, at $15^{\circ} \mathrm{C}$ upon rapid cooling from $55^{\circ} \mathrm{C} ; 4$, at $15^{\circ} \mathrm{C}$ after aging for 2 days at room temperature. 
mophore appears to be reversed by replacement of the acrylyloxyethyl group with the methyl group. The exciton coupling disappeared at $55^{\circ} \mathrm{C}$ where the bilayer is in the liquidcrystalline state, but it was regained by lowering the temperature to $15^{\circ} \mathrm{C}$. Similar temperature effects have been reported for non-polymerizable chiral bilayers. ${ }^{8}$ The bilayer prepared by polymerization at $20^{\circ} \mathrm{C}$ shows an exciton coupling with $[\theta]=-2.2 \times 10^{5}$ at $15^{\circ} \mathrm{C}$ (Figure $4 \mathrm{~b}$ ), indicating preservation of most of the original bilayer organization. This coupling disappeared at $55^{\circ} \mathrm{C}$ and was not recovered by the subsequent rapid cooling to $15^{\circ} \mathrm{C}$. However, it was regenerated after aging at room temperature for two days. On the other hand, the bilayer sample polymerized in a liquidcrystalline state $\left(50^{\circ} \mathrm{C}\right)$ gave $[\theta]_{\max }$ of only $-6,000$. The subsequent temperature variation $\left(15^{\circ} \mathrm{C} \rightarrow 55^{\circ} \mathrm{C} \rightarrow 15^{\circ} \mathrm{C}\right)$ did not induce significant spectral changes.

These CD data are consistent with the DSC data. The bilayer polymerized at $T<T_{\mathrm{c}}$ can regain the original component organization upon prolonged aging, but the molecular packing in the bilayer that is polymerized at $T>T_{\mathrm{c}}$ remains disordered even after aging.

\section{Fluorescence Emission}

Fluorescence spectra of bilayers of 3 , both unpolymerized and polymerized, are shown in Figure 5. The measurements were made by using the same samples as those used for the $\mathrm{CD}$ measurements. The unpolymerized sample gave a main emission at $320 \mathrm{~nm}$. This emission has been assigned to the monomer emission in the study of related, non-polymerizable bilayers. ${ }^{11}$ The monomer emission disappeared in the liquid crystalline state (at $55^{\circ} \mathrm{C}$ ), but the long-wavelength components at $350-400 \mathrm{~nm}$ still remained which have been ascribed to an excimer emission. ${ }^{11}$ The original emission pattern was recovered by lowering the temperature to $15^{\circ} \mathrm{C}$. The observed pattern of the temperature dependence is identical with that of the $C D$ spectrum. The bilayer polymerized in the crystalline state showed monomer and excimer emissions ${ }^{11}$ at $15^{\circ} \mathrm{C}$, and the former disappeared at $55^{\circ} \mathrm{C}$. This change is essentially the same as that observed for the unpolymerized bilayer. However, much stronger excimer emission appeared when the bilayer dispersion was rapidly cooled to $15^{\circ} \mathrm{C}$ (from $55^{\circ} \mathrm{C}$ ). Aging of the dispersion at room temperature for two days regenerated the original emission pattern. The bilayer polymerized in the liquid crystalline state gives a strong excimer emission at $15^{\circ} \mathrm{C}$, which was weakened at $55^{\circ} \mathrm{C}$. The strong excimer emission of Figures. $5 \mathrm{~b}$ and $5 \mathrm{c}$ must arise from a fixa-

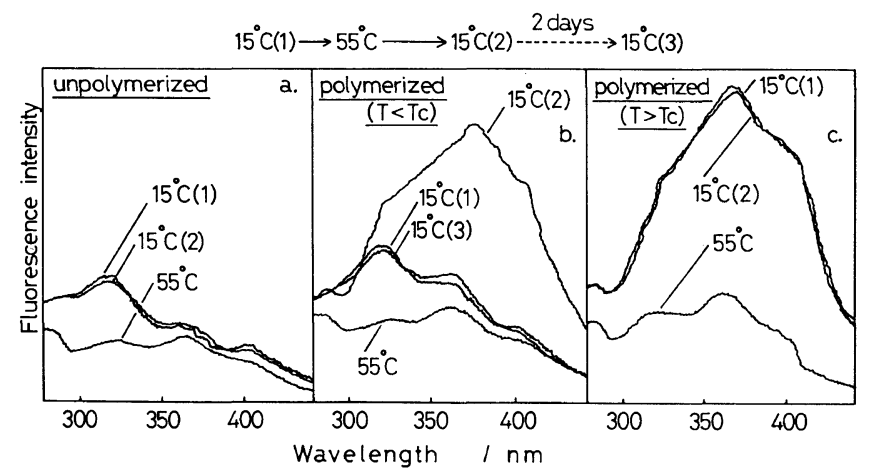

Figure 5. Fluorescence spectra of aqueous bilayer dispersions of unpolymerized and polymerized $2\left(\mathrm{C}_{12} \mathrm{OC}_{2}\right)$-L-GluPhC $\mathrm{N}^{+} \mathrm{Ac}$, 3. $0.1 \mathrm{mM}$. (a) unpolymerized; (b) polymerized at $20^{\circ} \mathrm{C}$ (below $T_{\mathrm{c}}$ ); (c) polymerized at $50^{\circ} \mathrm{C}$ (above $T_{\mathrm{c}}$ ). The sequence of measurement: 1 , the original dispersion at $15^{\circ} \mathrm{C} ; 2$, at $55^{\circ} \mathrm{C}$ upon rapid heating from $15^{\circ} \mathrm{C} ; 3$, at $15^{\circ} \mathrm{C}$ upon rapid cooling from $55^{\circ} \mathrm{C} ; 4$, at $15^{\circ} \mathrm{C}$ after aging for 2 days at room temperature. 


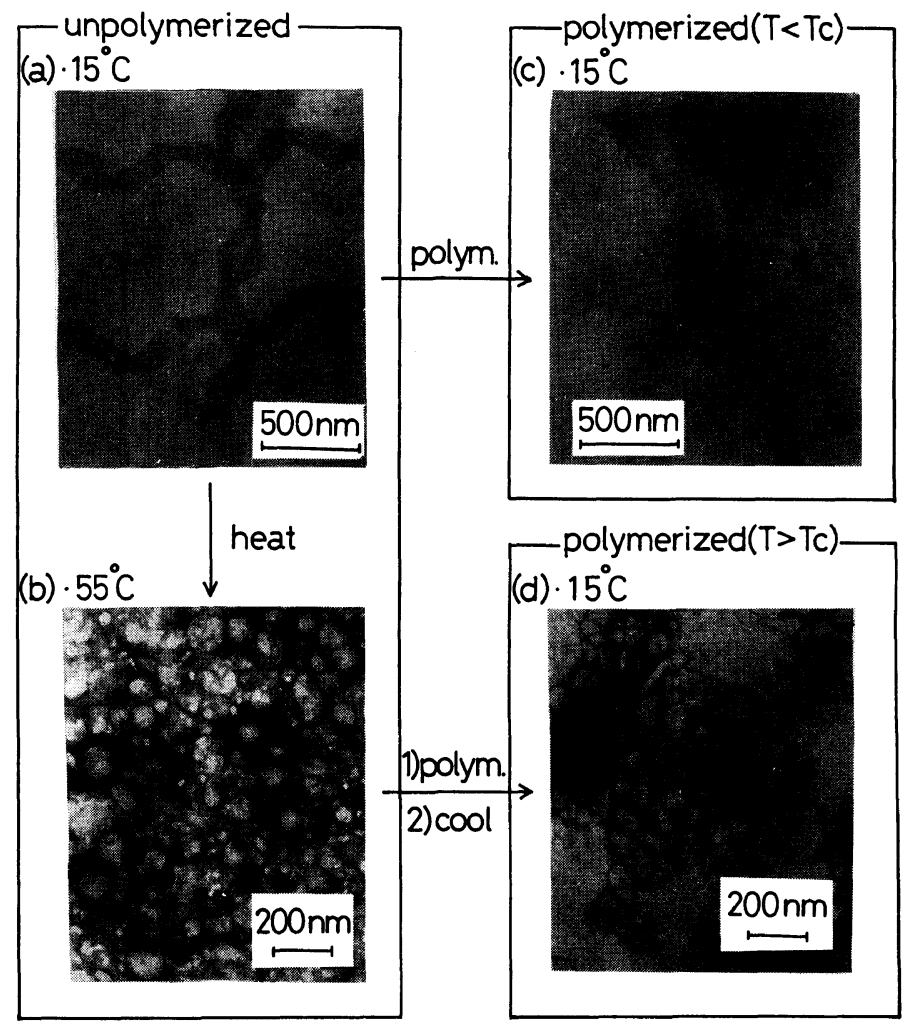

Figure 6. Electron micrographs of bilayer dispersions of unpolymerized and polymerized $2\left(\mathrm{C}_{12} \mathrm{OC}_{2}\right)-\mathrm{L}-$ $\mathrm{GluPhC}_{6} \mathrm{~N}^{+} \mathrm{Ac}$, 3. Stained by uranyl acetate. (a) unpolymerized, applied to $\mathrm{Cu}$ mesh at $15^{\circ} \mathrm{C}$; (b) unpolymerized, applied at $55^{\circ} \mathrm{C}$; (c) polymerized at $20^{\circ} \mathrm{C}$ (below $T_{\mathrm{c}}$ ), applied at $15^{\circ} \mathrm{C}$; (d) polymerized at $50^{\circ} \mathrm{C}$ (above $T_{\mathrm{c}}$ ), applied at $15^{\circ} \mathrm{C}$.

tion of partially disordered bilayer assembly.

\section{Transmission Electron Microscopy}

The DSC and spectral (CD and fluorescence) data are explained in relation to the extent of component alignment that is achieved under different conditions. These bilayer dispersions were then investigated by electron microscopy to know if the observed physicochemical changes are reflected in the aggregate morphology. The unpolymerized dispersion contained flexible fibers at room temperature. When kept at $15^{\circ} \mathrm{C}$, they were slowly transformed into helical superstructures as shown in Figure 6a. The aggregates were almost completely converted to helices after 4-5 days.

In contrast, when the liquid crystalline sample (at $55^{\circ} \mathrm{C}$ ) is applied to a $\mathrm{Cu}$ grid, globular aggregates with a diameter of $500-1000 \AA$ are found in place of the helices (Figure. 6b).

Some helical superstructures of Figure $6 \mathrm{a}$ were kept intact even after polymerized at $15^{\circ} \mathrm{C}$ (Figure 6c), although the amount of tread-like aggregates increased. The polymerization at $55^{\circ} \mathrm{C}$ produced vesicular aggregates with diameters of 500 to $1000 \AA$ and helices were not formed even after cooling to room temperature (Figure 6d). This morphology is very similar to that observed in the liquid crystalline state $\left(55^{\circ} \mathrm{C}\right)$ before polymerization.

We have shown previously, chiral bilayer membranes were readily transformed into helical superstructures by an appropriate 


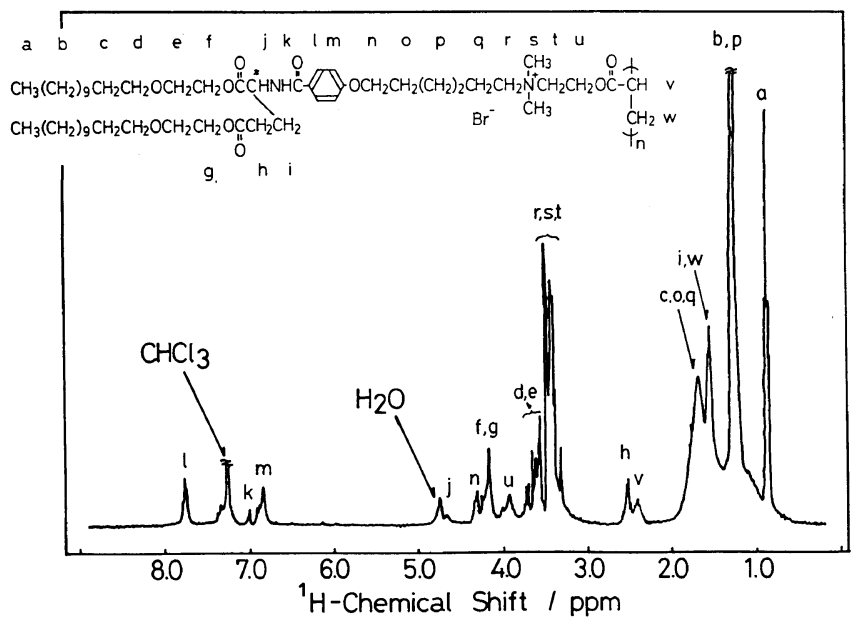

Figure 7. $400 \mathrm{MHz}{ }^{1} \mathrm{H}$ NMR spectrum of $2\left(\mathrm{C}_{12} \mathrm{OC}_{2}\right)-\mathrm{L}-\mathrm{GluPhC} \mathrm{C}_{6} \mathrm{~N}^{+} \mathrm{Ac}, 3$. polymerized at $20^{\circ} \mathrm{C}$ (below $\left.T_{\mathrm{c}}\right) . \mathrm{CDCl}_{3}$, TMS internal standard, $30^{\circ} \mathrm{C}$.

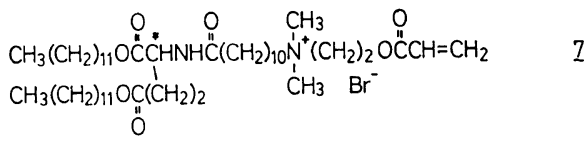

incubation. ${ }^{12-14}$ Glutamate-based ammonium amphiphiles were particularly suitable for this transformation. In our previous study, ${ }^{2}$ polymerization of 7 completely destroyed helices, probably because constriction by the polymer chain disturbed the alignment of side chains.

\section{${ }^{1} \mathrm{H}$ NMR Measurement}

Different behaviors of bilayers polymerized at different temperatures might be explained in terms of their structural differences. We therefore measured $400 \mathrm{MHz}{ }^{1} \mathrm{H}$ NMR spectra of $\mathrm{CDCl}_{3}$ solutions. Figure 7 shows a ${ }^{1} \mathrm{H}$ NMR spectrum of the polymer obtained at $20^{\circ} \mathrm{C}$. The spectral pattern agrees with what is expected from the conventional vinyl polymerization, as is clear from the inserted assignments. The polymer obtained at $50^{\circ} \mathrm{C}$ gives an identical spectrum indicating that its limited dispersibility in water cannot be ascribed to extensive structural difference. Another possibility for the different behavior is tacticity difference. Regen and coworkers reported the tacticity difference due to polymerization temperature among poly(methacrylate) counteranions of ammonium bilayer vesicles. ${ }^{15}$ However, it was not possible to determine the tacticity of the present polymer.

\section{Redispersion of Polymerized Bilayers}

Bilayer-forming amphiphiles usually possess small hydrophile-lipophile balances and cannot be dispersed in water unless they form well-organized assemblies. In this respect, dispersibility of the polymerized bilayer has an important bearing on its ease of molecular alignment.

The polymerized dispersion $(20 \mathrm{mM})$ of 3 were spread on Fluoropore films, water was evaporated in vacuo, and the residues (small pieces of thin films) were sonicated in deionized water. The bilayer polymerized at $20^{\circ} \mathrm{C}$ was only partially re-dispersible at the same concentration, but was completely dispersed upon dilution (at $6.7 \mathrm{mM}$ ). DSC measurement of this sample showed a small peak at $45.0^{\circ} \mathrm{C}$ $\left(\Delta H=10.3 \mathrm{~kJ} \mathrm{~mol}^{-1}\right)$ upon aging for one day. The peak became intense with the prolongation of aging time, and reached a maximal value $\left(\Delta H=29.5 \mathrm{~kJ} \mathrm{~mol}^{-1}, \quad \Delta S=92.7 \mathrm{~J} \mathrm{~K}^{-1} \mathrm{~mol}^{-1}\right)$ which was identical with that of the as- 
(a)

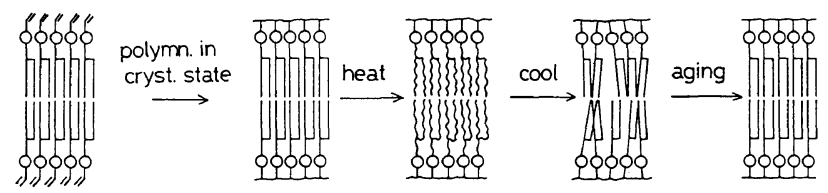

(b)

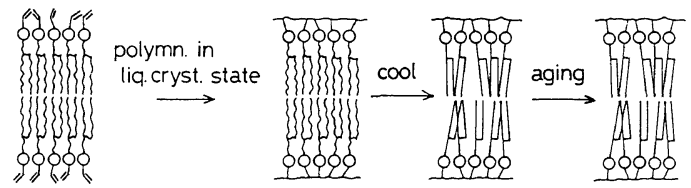

Figure 8. Schematic illustration of the molecular orientation of bilayers of $2\left(\mathrm{C}_{12} \mathrm{OC}_{2}\right)-\mathrm{L}-\mathrm{GluPhC}_{6} \mathrm{~N}^{+} \mathrm{Ac}$, 3. (a) for a bilayer sample polymerized below $T_{\mathrm{c}}$, (b) for a bilayer sample polymerized above $T_{\mathrm{c}}$.

polymerized sample. Therefore, the original bilayer organization can be recovered by 4-day aging. In contrast, the bilayer polymerized at $50^{\circ} \mathrm{C}$ could not be dispersed wither at $20 \mathrm{mM}$ or at $6.7 \mathrm{mM}$.

A facile reorganization of alkyl chains is indispensable for the spontaneous alignment. Structures of the polymers obtained at $T>T_{\mathrm{c}}$ and at $T<T_{\mathrm{c}}$ were not discriminated by $400-\mathrm{MHz}{ }^{1} \mathrm{H}$ NMR spectroscopy. The mainchain stereochemistry appears to be responsible for the above-mentioned different behaviors. The bilayer polymerized at $T<T_{\mathrm{c}}$ should possess a stereochemistry which is favarable for the side-chain alignment.

\section{CONCLUSION}

The present results emphasize the importance of proper molecular design in order to achieve simultaneously ready polymerizability and facile packing of side chains in the polymerized bilayer. A phenyl group in the spacer portion and an ether linkage in the tail portion of alkyl chain are key points of molecular design in the glutamate-based bilayer. The physical state of bilayer membrane during polymerization exerts and additional influence on the property of the polymerized bilayer. Figure 8 schematically represents the relation between thermal treatment and chain alignment. Thus the bilayer polymerized in the crystalline state undergoes phase transition similar to that of the unpolymerized counterpart, although recovery of the original chain packing is slow. In contrast, the bilayer which is polymerized in the liquid crystalline state possesses a certain extent of disorder even after a prolonged aging. The different characteristics of polymerized bilayers which we observed in the study are related to their stabilities as surface monolayers on water ${ }^{16}$ and as black lipid membranes (BLM). ${ }^{17}$ A consistent picture will emerge from these studies concerning molecular design of membrane materials.

\section{REFERENCES}

1. Contribution No. 925 from Department of Organic Synthesis.

2. Part I, T. Kunitake, N. Nakashima, and M. Kunitake, Macromolecules, 22, 3544 (1989).

3. J. H. Fendler and P. Tundo, Acc. Chem. Res., 17, 3 (1984).

4. H. Ringsdorf, B. Schlarb, and J. Venzmer, Angew. Chem. Int. Ed. Engl., 27, 113 (1988).

5. T. Kunitake, N. Nakashima, K. Takarabe, M. Nagai, A. Tsuge, and H. Yanagi, J. Am. Chem. Soc., 103, 5945 (1981).

6. R. Elbert, A. Laschewsky, and H. Ringsdorf, J. Am. Chem. Soc., 107, 4134 (1985).

7. N. Kimizuka, T. Takasaki, and T. Kunitake, Chem. Lett., 1988, 1911.

8. T. Kunitake, N. Nakashima, M. Shimomura, Y. Okahata, K. Kano, and T. Ogawa, J. Am. Chem. 
Soc., 102, 6642 (1980).

9. T. Kunitake, R. Ando, and Y. Ishikawa, Mem. Fac. Eng., Kyushu Univ., 46, 221 (1986).

10. T. Takasaki and S. Kato, unpublished results in these laboratories.

11. T. Kunitake, S. Tawaki, and N. Nakashima, Bull. Chem. Soc. Jpn., 56, 3235 (1983).

12. N. Nakashima, S. Asakuma, J.-M. Kim, and T. Kunitake, Chem. Lett., 1709 (1984).
13. N. Nakashima, S. Asakuma, and T. Kunitake, J. Am. Chem. Soc., 107, 509 (1985).

14. T. Kunitake and N. Yamada, J. Chem. Soc., Chem. Commun., 655 (1986).

15. S. L. Regen, N. K. P. Samuel, and J. M. Khurana, J. Am. Chem. Soc., 107, 5804 (1985).

16. S. Kato, Y. Ishikawa, and T. Kunitake, Polym. Prepr. Jpn., 38, 2471 (1989).

17. S. Kato, unpublished results in these laboratories. 